\title{
A desconstrução da psicossomática na análise existencial de Heidegger e Boss
}

\author{
Ana Maria Lopez Calvo de Feijoo*1 \\ Cristine Monteiro Mattar*2
}

O presente artigo coloca em questão a compreensão tradicional da psicossomática por meio da dicotomia soma e psique e a relação de causalidade presente nessa tradição para, então, mediante uma perspectiva crítica, propor outra compreensão, com base na fenomenologia-hermenêutica de Heidegger e a Daseinsanálise de Boss. Este coloca, ainda, em questão a denominação psicossomática que mantém a dualidade da qual se pretende libertar.

Palavras-chave: Psicossomática, análise existencial, Heidegger, Boss

${ }^{*}{ }_{1}$ Universidade do Estado do Rio de Janeiro - UERJ (Rio de Janeiro, RJ, Br).

*2 Universidade Federal Fluminense - UFF (Niteroi, RJ, Br). 
O termo "psicossomática" surgiu no século passado, com o médico alemão Heinroth (1773-1843). Heinroth, em 1818, apresenta uma publicação intitulada Desordens da alma; já em 1828, aparece em seus escritos a denominação "somatopsíquica". Assim, no médico alemão podemos distinguir dois tipos diversos que influenciam suas obras, bem como suas diferentes direções: a alma e a dicotomia soma e psíquico. Esse psiquiatra acreditava, primeiramente, naquilo que ele denominou de desordens da alma, que se referia à influência das paixões sexuais no aparecimento de algumas doenças, como a tuberculose, a epilepsia e o câncer e a insônia. Após dez anos, ele introduziu o termo "somatopsíquico" ao referir-se à influência de fatores orgânicos nos efeitos emocionais, com o poder de modificar o estado psíquico (Castro, Andrade \& Müller, 2006; Silva \& Müller, 2007).

Essa forma de pensar as doenças do soma como expressão do psíquico, de maneira geral, encontra-se presente na atualidade sob a denominação de medicina psicossomática, pela qual o psiquiatra se orienta, quando inserido no hospital geral, a fim de que este se prepare para a interconsulta, quando solicitado (Blumenfield \& Tiamson-Kassab, 2010). O psiquiatra com essa orientação deverá estar atento aos sintomas psíquicos vistos como efeitos previsíveis de diversos tipos de adoecimento, bem como aos problemas de origem psíquica que poderão resultar em disfunções orgânicas. Tal classificação chama a atenção, pelo empenho em categorizar os chamados fenômenos psicossomáticos ou somatopsíquicos, apontando para a gênese do transtorno ora no corpo, ora na psique, bem como estabelecendo relações de causalidade entre as duas instâncias, que são tomadas como dicotômicas. A perturbação em uma delas pode gerar efeitos na outra, o que leva a uma prática que requer a atuação de dois profissionais, o médico a quem cabe o tratamento do somático e o psiquiatra e/ou psicólogo aos quais fica designada a psico-oncologia, ou seja, o tratamento dos efeitos psicológicos decorrentes da doença, como a depressão, a ansiedade, o medo dos tratamentos, o medo da morte. Assim, toda a compreensão das enfermidades passa a ser tomada em uma dualidade soma e psique. Isso acaba por criar um fosso entre a existência e a teoria que, muitas vezes, é motivo de descrença, seja por parte do médico, do profissional psi ou mesmo do leigo. O médico quando imbuído dessa descrença acaba por reduzir tudo ao somático, já o profissional psi reduz ao psíquico e o leigo ou fica em uma ou outra interpretação. Com a referência dicotômica e causalista, chega-se a obscurecer a unidade mais 


\section{ARTIGO}

originária, em que a existência não aparece por estar em meio à disjunção. O mais originário desse aparecer é que cria a condição de possibilidade de surgimento do soma e psique dicotomizados. Como nos diz Heidegger (2001), o soma e a psique são tardios. Parece que esse obscurecimento é a marca de nosso tempo, predominando na forma de pensar dicotomicamente o fenômeno da psicossomática.

As temáticas do corpo e da psicossomática foram abordadas por Heidegger durante os Seminários de Zollikon (2001), colocando em questão as noções de saúde, corpo e doença tal como abarcadas em uma perspectiva científico-natural. Heidegger, com isso, queria exercitar outro olhar para essas mesmas questões. Para tanto, ele, inspirado na fenomenologia, dá um passo atrás com relação às interpretações vigentes e acompanha tais fenômenos por um viés hermenêutico. O filósofo alemão lembra que é preciso se demorar naquilo que é tido como óbvio, e, por isso, permanece não tematizado e pouco questionado, em seu sentido originário. Sobre a questão do corpo, por exemplo, afirma Heidegger: "Trata-se de reconhecer em que consiste, primariamente, o problemático do problema do corpo" (Heidegger, 2001, p. 104). Para se deter sobre essa questão, ele vai partir de uma conferência do médico Hegglin no Primeiro Congresso da Sociedade Psicossomática da Suíça.

\section{A questão da psicossomática nos Seminários de Zollikon}

Heidegger, ao tecer considerações sobre a tese de Hegglin, esclarece que não se trata de desconsiderar a proposta do médico, mas de criticá-la no sentido grego, ou seja, diferenciar, realçar as diferenças, deixar ver. Quando, por exemplo, diferenciamos o verde e o vermelho a partir de algo que nos é dado como a cor, a cor é esse mesmo com referência ao qual a diferenciação pode ser feita.

Assim, o que Heidegger pretende, nesse texto, é deixar aparecer no que foi dito aquilo que se retrai, para assim poderem aparecer outras formas de visada do fenômeno da psicossomática. Para que seja possível desdobrar o psicossomático como problema é necessária uma crítica verdadeira, fenomenológica, que permita primeiramente diferenciar o psíquico e o somático a partir de um mesmo, o ser do homem como homem. No tema da psicossomática há uma diferenciação que se refere a esse mesmo e uno. As pesquisas científicas não tornam evidente o ser do ente em sua propriedade, o ente de que se trata em cada caso. Na psicossomática, "trata-se do ser-homem do homem" (Heidegger, 2001, p. 104).

Ao referir-se à conferência de Hegglin, Heidegger (2001) afirma que o conferencista quer resumir todas as influências mútuas de psique e soma sob o conceito de Psicossomática, em vez de reivindicar essa expressão somente para 
as doenças emocionais. Haveria, assim, na visão desse médico, as doenças psicossomáticas, quando problemas emocionais afetam o corpo, e as doenças somatopsíquicas, quando problemas corporais afetam o psíquico. Diz o médico que pretende excluir especulações filosóficas para ater-se ao princípio simples que defende para diferenciar soma e psique. Para Hegglin, a diferença entre esses dois elementos é que os fenômenos psíquicos não podem ser pesados nem medidos, só podem ser sentidos intuitivamente, enquanto o somático pode ser apreendido por números. Assim, exemplifica: o luto não pode ser medido, mas as lágrimas podem ser examinadas numericamente. Assim, Hegglin abandona a unidade, ser-homem do homem, que sustenta a polaridade soma e psique.

Heidegger (2001) diz que Hegglin abandona o elemento mais originário, o uno, e inaugura um princípio simples para a diferenciação entre psique e soma. O princípio estabelecido por Hegglin, que diz que soma e psique são fenômenos separados, irá determinar, dominar e conduzir todo o conhecimento que virá a seguir acerca do fenômeno psicossomático.

Na conferência de Heglin, o princípio de diferenciação de soma e psique é a maneira da compreensão diferente de soma e psique e diz: os fenômenos psíquicos não podem ser pesados, medidos, são sentidos intuitivamente; tudo que é somático pode de alguma forma ser compreendido por números. "Os dois âmbitos temáticos, psique e soma, são, pois, definidos (por Hegglin) em seu conteúdo a partir do modo de acesso a eles. O modo de investigação do âmbito de ser, o acesso a este, é referente à sua cognoscibilidade" (Heidegger, 2001, p. 106). O método de acesso a ambos tornou-se mais valorizado do que os próprios fenômenos psíquicos e somáticos. O fato de serem ou não mensuráveis passou a ser o critério de sua diferenciação. Trata-se de uma supervalorização do método em detrimento do fenômeno.

Heidegger pergunta se, a partir do modo de acesso a um âmbito, seu conteúdo pode ser determinado em ser-o-que-e-como. De que modo a maneira de acesso é determinada?

Hegglin diz que os fenômenos psíquicos só podem ser sentidos intuitivamente e não são mensuráveis. Heidegger questiona: "Por que razão o modo de acesso ao psíquico é a intuição, enquanto para o somático é a mensuração?" (Heidegger, 2001, p. 106). A razão está no modo de ser da psique e do soma. O princípio simples do médico diz: os âmbitos temáticos de psique e soma são determinados pelo respectivo modo de acesso, e o modo de acesso é determinado pela coisa, pelo soma e pela psique.

Heidegger diz que o "princípio simples" apresentado para a diferenciação entre psique e soma "não é tão simples" (Heidegger, 2001, p. 107), e nos confronta com a pergunta: o que acontece com a diferenciação entre psique e soma, como ela deve ser feita? E conclui: "A questão do psicossomático é, em 


\section{ARTIGO}

primeiro lugar, uma questão de método" (Heidegger, 2001, p. 107). O método científico natural produz o somático como mensurável em oposição ao psíquico, constituindo-os a partir do a priori da mensuração, como se esta fosse natural e necessária. No entanto, já se trata de um olhar que produz a verdade dos fenômenos como sendo mensuráveis ou não mensuráveis.

Voltando à conferência, que fala ainda em fundamentos das conexões entre soma e psique, Heidegger indaga o que isso significa. Significa algo para o qual se pode exigir uma prova científico-natural. Entretanto, uma prova científico-natural para essa conexão entre psique e soma nem é possível, pois, pela exigência científica, esses fundamentos deveriam ser somáticos, pois só o somático seria mensurável, e só o que é mensurável pode ser provado de modo científico-natural. A prova não poderia apoiar-se em apenas um dos dois âmbitos em questão, o somático.

Aquilo que corresponde à exigência de conhecimento válido do cientista natural deve ser provável e provado pela mensuração. O autor da conferência exige que a relação entre soma e psique seja mensurável. Exigência injustificada, pois não provém da relação dos fatos em questão, mas sim da exigência e do dogma científico-natural: só seria real o que fosse mensurável. "Mas então as conexões entre psique e soma seriam algo psíquico, algo somático ou nem um nem outro?" (Heidegger, 2001, p. 107). Heidegger propõe, então, outro método para tentar sair do que chama de beco sem saída.

\section{A questão do corpo na perspectiva heideggeriana}

Heidegger, também nos Seminários de Zollikon (2001), volta-se, então, para o problema do corpo. Retoma Ser e tempo (1927/1989), no parágrafo 23, onde fala sobre a espacialidade do ser-no-mundo e que a compreensão do corpo como aquilo que termina na epiderme está totalmente equivocada, $\mathrm{O}$ corpo vai muito além de sua materialidade, por isso nele se incluem seus direcionamentos. Podemos estar próximos de algo que, no entanto, não é uma extensão de nosso direcionamento, assim como podemos ouvir um barulho distante que nos faz tremer. Tudo isso nos mostra que o corpo transcende a epiderme.

O Dasein do homem é espacial em si, porque ordena o espaço e porque há uma espacialização do Dasein em sua corporeidade. "O Dasein não é espacial por ser corporal, mas sim a corporeidade só é possível porque o Dasein é espacial no sentido de ordenar" (Heidegger, 2001, p. 108).

Heidegger tenta, em seguida, alcançar a proximidade do fenômeno do corpo, mas sem a expectativa de solucionar o que chamou de problema do corpo. 
Para ele, já é muito conseguir apenas ver o problema. Ele insiste na dificuldade de diferenciar o psíquico do somático e novamente se remete à tese de Hegglin, afirmando que as lágrimas não podem ser medidas. No máximo, se mede um líquido e suas gotas, mas não lágrimas, que só podem ser vistas diretamente. As lágrimas não são algo somático nem algo psíquico.

Em outro exemplo, alguém enrubesce de vergonha e embaraço. O enrubescer também não pode ser medido. Mede-se, no máximo, a vermelhidão, pelo fornecimento de sangue. O enrubescimento não é algo somático nem algo psíquico. Assim, os critérios de separação do soma e psique pela possibilidade de medição, defendidos por Hegglin e pela ciência para diferenciar o somático do psíquico, caem por terra.

Fenomenologicamente, o enrubescimento da face ao envergonhar-se pode ser diferenciado daquele pela febre ou a entrada em um abrigo quente. Os três tipos acontecem na face, embora sejam muito diferentes e diretamente diferenciados por nós no ser-com-os-outros quotidiano. Vemos no rosto do próximo se ele está constrangido ou aquecido, e tal leitura só pode ser feita por sermos com os outros, logo, prescindindo de critérios objetivos.

É o fenômeno como fenômeno que Heidegger propõe que devemos 656 alcançar. Ver no rosto do outro a tristeza é possível, devido ao ser-com cotidiano, mas medir a tristeza não é possível. Dizer que alguém está um pouco triste não significa uma quantidade pequena de tristeza. $\mathrm{O}$ um pouco significa um modo (qualidade) de afinação. Ou seja, não posso apreender e medir objetivamente a profundidade da tristeza.

O corpo, que nos parece o mais próximo, é o mais distante no espaço. Quando se tem dor nas costas, diz-se que ela se estende pelas costas, mas trata-se aí de outra espécie de espacialidade, que não é a extensão de superfície de um corpo material. Heidegger estabelece a diferença entre Leib, corpo material e Körper, fenômeno corporal, e que: “(...) a experiência do leigo é mais próxima do fenômeno da dor como fenômeno corporal, embora seja praticamente impossível descrevê-lo com a ajuda da nossa visão de espaço habitual" (Heidegger, 2001, p. 111). À técnica do exame do corpo material Heidegger contrapõe a experiência do leigo do corpo vivido, como sendo muito mais próxima de sua dor.

Heidegger afirma, por fim, que tentou tornar visíveis certos fenômenos como o enrubescer, a dor, a tristeza, deixando esses fenômenos ficarem simplesmente da maneira como os vemos, sem qualquer tentativa de reconduzi-los a qualquer coisa. Deve-se evitar qualquer tipo de possibilidade de relacioná-los e considerar até que ponto esses fenômenos já estão suficiente e completamente determinados em seu próprio conteúdo e se apontam para outros fenômenos aos quais pertençam essencialmente. 


\section{ARTIGO}

Ao falar desses fenômenos, faz-se o mesmo que desocultar, mostrar, desvelar, deixar vir à luz e zelar por eles como gestos. $O$ gesto, que na etimologia alemã vem de portar, carregar, trazer, tem a mesma origem de gestar, $G e$, que significa estar numa reunião. $\mathrm{O}$ gesto seria um conjunto de comportamentos e todo comportamento do ser humano um ser-no-mundo determinado pelo corporar do corpo. Cada movimento do meu corpo não entra simplesmente em um espaço indiferente como um gesto, como um comportamento desse ou daquele modo. $\mathrm{O}$ comportamento já está sempre numa região determinada que está aberta através da coisa com que está relacionado, quando, por exemplo, pego algo na mão. "O corporar copertence sempre ao ser-no-mundo. Ele codetermina sempre o ser-no-mundo, o ser-aberto, o ter de mundo" (Heidegger, 2001, p. 123). Sendo assim, o ser-no-mundo jamais pode prescindir do corporar.

\section{Daseinsanálise e psicossomática}

Medard Boss em sua obra Introdução à medicina psicossomática, de 1959, também aponta para outra possibilidade de pensar as relações soma e psique. Acompanhando a linha de pensamento de Heidegger, Boss coloca em questão as tentativas de explicação do adoecer por uma somatogênese ou por uma psicogênese, que classifica como duvidosas.

Boss (1959) vai passar a pensar o adoecer em uma perspectiva daseinsanalítica. Ele defende que todo o adoecer é sempre psicossomático, pois atinge a abertura que é o Dasein, ser-aí, como um todo, e representa uma restrição a determinada possibilidade, a doença com suas limitações, em detrimento de outras. Algo que nos atinge física ou psiquicamente já nos afetou de maneira mais originária, tendo em vista a nossa existência como abertura antes de tudo. Em cada adoecer, sugere Boss (1959), deve-se perguntar qual é a relação com o mundo que se encontra perturbada, quais as possibilidades existenciais que um determinado adoecer impede que se realizem.

Sobre o corpo, com base nas reflexões de Heidegger (2001), nos diz Boss (1959): "O corpo constitui uma condição necessária, mas em nenhum caso $a$ condição suficiente da existência humana" (p. 31). Nossos órgãos sensoriais, como soma, funcionam por meio dos olhos, dos ouvidos, da língua, da pele, porém eles não podem ver, escutar, sentir, provar ou tocar. Apenas pela e na corporeidade o homem se relaciona com aquilo que lhe vem ao encontro.

Ainda, com base nas considerações de Heidegger sobre o corpo, o médico suíço afirma que a presença humana não se limita ao espaço ocupado pelo corpo. A corporeidade é uma das esferas do nosso ser, nela se atualiza a existência 
humana, que engloba os fenômenos do "corpo" e da "alma", do somático e do psíquico. Embora, diferentes, ambos constituem aspectos de uma mesma estrutura originária que é a existência humana, o modo de ser do homem, isto é, o Dasein ou ser-aí. A partir dessa abertura é que se pode vir a falar em soma e psique. A corporeidade humana como esfera da existência se atualiza de modo físico ou somático. O aspecto corporal é o modo físico de relações com o mundo, relações que definem o que o Dasein é. A doença é uma estagnação de possibilidades vitais na corporeidade. A existência estagnada e reduzida somente à corporeidade aparecerá sob um aspecto patológico e anormal.

Será, então, com base na concepção de corpo, existência e doença em sua totalidade que Boss (1959) vai apresentar as suas interpretações sobre a medicina psicossomática. Assim, ele irá mostrar diferentes situações que apontam para o modo de corporar do Dasein, dentre elas, a predisposição aos acidentes, a hipertensão arterial ou idiopática, as afecções crônicas idiopáticas do aparelho digestivo e a asma bronquial.

Com relação à predisposição aos acidentes, primeiramente Boss (1959) pesquisa como os acidentes acontecem e estuda as diferentes interpretações acerca desse fenômeno. Algumas interpretações de cunho psicológico referiam-se ao desejo inconsciente de mutilar-se, de penalizar-se e até como tentativa de suicídio. As interpretações em uma perspectiva social assinalavam, por meio de pesquisas das seguradoras acerca das causas dos acidentes, o aumento do uso de máquinas com o consequente aumento no número de acidentes e outras defendiam os acidentes como sendo da ordem do acaso. Boss (1959), dedicando-se a estudar tais pesquisas, conclui que a maioria dos acidentes acontecia por falha humana por parte dos próprios acidentados. Ele chega, inclusive, a observar a reincidência de acidentes, nas mesmas pessoas, caracterizando como pessoas predispostas aos acidentes. Boss (1959) junta a essas informações os seus estudos clínicos e conclui que essas pessoas vivem em estado de tensão contínua em relação ao meio ambiente. Logo, esse psiquiatra conclui que a tensão na situação desse ser-aí no mundo é o espaço mais originário em que a predisposição aparece.

Quanto à hipertensão essencial ou idiopática, Boss (1959) nos mostra que aqueles que tentaram interpretar essa predisposição como algo geneticamente determinado, afirmando que se tratava de uma doença que acometia os negros, tiveram suas teses desconsideradas quando outro grupo de pesquisadores mostrou que os negros que viviam na África não apresentavam hipertensão. Diz Boss que os negros americanos, diferentemente dos negros africanos, vivem e corporalizam a existência como uma pressão constante. Essa pressão acontece de forma tal que os vasos sanguíneos se tornam espessos, calcificados e a corrente sanguínea passa a ser submetida a uma pressão crescente até que um vaso invisível ceda e o liberte do peso esmagador da vida. Podemos concluir, junto às considerações de Boss, 


\section{ARTIGO}

que a hipertensão é uma expressão do Dasein em sua totalidade e, portanto, não pode ser reduzida ao soma ou à psique.

Já as afecções crônicas idiopáticas do aparelho digestivo, segundo Boss (1959), ocorrem frequentemente em pessoas cuja existência se restringe a uma concentração extrema em torno de seu propósito da vida. Por exemplo, na vida profissional, a sua vida se concentra na extrema dedicação. No entanto, pela idealização inalcançável de seu projeto, acabam sempre frustradas. Por restringir suas possibilidades, desconhecendo as outras, elas não podem senão tentar sem cessar alcançar a conquista da felicidade pelo acúmulo de bens materiais, de bens que lhes permitam desempenhar um papel. Tornam-se obcecadas pelo impossível e, atendo-se apenas a essa possibilidade, têm uma ação incessante que desconhece limites, terminando por se expressar no mundo por úlceras estomacais, dentre outras patologias do sistema digestivo.

$\mathrm{Na}$ asma bronquial, para Boss (1959), trata-se do corporar a existência da forma mais vulnerável possível. O fenômeno é corporado por contrações asmáticas dos bronquíolos e dos brônquios. Trata-se de um sufocamento pela suspensão da respiração, fato esse vivido de forma aterrorizante, pois sem ar não se vive mais do que dois ou três minutos. A realização corporal de uma existência que, sem ar, chega ao mundo que, embora pleno de excitações, reduz-se a um desespero pela restrição e desamparo frente ao não poder respirar. Para Boss, a asma bronquial está intimamente relacionada à tentativa fracassada de controlar a condição de desamparo que é própria da existência.

\section{Considerações finais}

Iniciou-se falando sobre a dicotomia presente na compreensão da psicossomática, ora relacionada a uma somatogênese, ora a uma psicogênese, a fim de preparar-se o caminho para mostrar as diferenças em relação ao tema em uma perspectiva mais originária, fenomenológico-hermenêutica e daseinsanalítica.

Acompanhou-se Heidegger (2001) em sua proposta de que a corporeidade essencial do Dasein integra o gesto, que reúne e revela todos os comportamentos do ser-no-mundo. O psíquico e o somático são expressões desse gesto originário e uno. Nessa perspectiva, não caberia mais nem mesmo a denominação de psicossomática. Sobre isso questiona Boss $(1959$, p. 4), ao apresentar o seu livro, o próprio uso do termo psicossomática, o qual ainda manteria a dualidade que se deseja abandonar, estando longe de uma terminologia adequada à essência do adoecer humano. Busca assim, esse autor, afastar-se da tradição que considera o homem como sendo uma composição de corpo, alma e espírito. Por ser o termo 
psicossomática incômodo e imperfeito, explica Boss (1959) que, em sua obra, pretende estar menos preso à terminologia, a fim de buscar "uma descrição fiel dos fenômenos" e que somente essa tarefa já exigiria "uma longa investida e um novo olhar" (p. 4).

\section{Referências}

Blumenfield, M., \& Tiamson-Kassab, M. (2010). Medicina psicossomática. Porto Alegre: Artmed.

Boss, M. (1959). Introduction a la medicine psychosomatique. Paris: Presses Universitaires de France.

Castro, M. G.; Andrade, T. M. R., \& Müller, M. C. (2006, jan-abr.). Conceito mente e corpo através da história. Psicologia em Estudo, 11(1), 39-43.

Heidegger, M. (1989). Ser e tempo. Petrópolis, RJ: Vozes. (Trabalho original publicado em 1927).

Heidegger, M. (2001). Seminários de Zollikon. Petrópolis, RJ: Vozes.

Silva, J.D.T. \& Müller, M.C. (2007, Apr-Jan.). Uma integração teórica entre psicossomática, stress e doenças crônicas de pele. Estudos de Psicologia, 24(2), 247-256.

\section{Resumos}

(The deconstruction of psychosomatics in Heidegger's and Boss' Daseinsanalysis)

This article brings into question the traditional understanding of psychosomatics by taking into account the dichotomy between soma and psyche and the causal relation present in this tradition. It suggests, from a critical point-of-view, a different understanding based on Heidegger's phenomenology-hermeneutics and Boss' Daseinsanalysis. This article also calls into question the term 'psychosomatics', which preserves the duality that has to be eliminated.

Key words: Psychosomatics, existential analysis, Heidegger, Boss

(La déconstruction de la psychosomatique dans la Daseinsanalyse de Heidegger et de Boss)

Cet article remet en question le concept traditionnel de la psychosomatique au moyen de la dichotomie entre soma et psyché et du rapport de causalité qui caractérise cette tradition. Par la suite, il propose, à partir d'un point-de-vue critique, une autre compréhension basée sur la phénoménologie herméneutique de Heidegger et sur la 


\section{ARTIGO}

Daseinsanalyse de Boss, et met également en question le terme "psychosomatique » qui préserve la dualité qu'on cherche à supprimer.

Mots clés: Psychosomatique, Daseinsanalyse, Heidegger, Boss de Boss)

(La deconstrucción de la psicosomática en el análisis existencial de Heidegger y

El presente artículo cuestiona la comprensión tradicional de la psicosomática mediante la dicotomía soma y psique, además de la relación de causalidad presente en esa tradición para proponer, a través de una perspectiva crítica, otro entendimiento basado en la fenomenología-hermenéutica de Heidegger y en el análisis del Dasein de Boss, que además pone en entredicho la palabra "psicosomática", que mantiene la dualidad de la cual pretende liberarse.

Palabras clave: Psicosomática, análisis existencial, Heidegger, Boss

(Die Dekonstruktion des Psychosomatischen in der Daseinsanalyse von Heidegger und Boss)

Dieser Artikel stellt das traditionelle Konzept des Psychosomatischen in Frage und stützt sich dabei auf die Dichotomie zwischen Soma und Psyche, sowie auf die Kausalitätsbeziehung, die dieser Tradition zu eigen ist. Mittels einer kritischen Perspektive schlägt dieser Artikel ein neues Konzept vor, das auf Heideggers Phänomenologie-Hermeneutik und der Daseinsanalyse von Boss basiert. Boss stellt dabei den Begriff ,,Psychosomatik“ in Frage, da er die Dualität beinhaltet, von der man sich zu befreien versucht.

Schlüsselwörter: Psychosomatik, Daseinsanalyse, Heidegger, Boss

(在海德格尔和博斯的存在注意分析的心身解构)

本文提出分析对心身的传统, 其对索玛和精神的二分法及因果关系。在此 基础上再通过所以通过海德格尔的现象一诠释学和博斯的存在分析从一个批判的 角度建立另一个认识。他虽然希望脱离但还保持身心定义中的双重性。

关键词：心身，存在分析，海德格尔，博斯 
Citação/Citation: Feijoo, A.M.L.C., Mattar, C.M. (2015, dezembro). A desconstrução da psicossomática na análise existencial de Heidegger e Boss. Revista Latinoamericana de Psicopatologia Fundamental, 18(4), 651-662.

Editores do artigo/Editors: Prof. Dr. Manoel Tosta Berlinck e Profa. Dra. Sonia Leite

Recebido/Received: 25.4.2014/ 4.25.2014 Aceito/Accepted: 25.6.2014 / 6.25.2014

Copyright: (C) 2009 Associação Universitária de Pesquisa em Psicopatologia Fundamental/ University Association for Research in Fundamental Psychopathology. Este é um artigo de livre acesso, que permite uso irrestrito, distribuição e reprodução em qualquer meio, desde que o autor e a fonte sejam citados / This is an open-access article, which permits unrestricted use, distribution, and reproduction in any medium, provided the original authors and sources are credited.

Financiamento/Funding: As autoras declaram não ter sido financiadas ou apoiadas / The authors have no support or funding to report.

Conflito de interesses/Conflict of interest: As autoras declaram que não há conflito de interesses / The authors have no conflict of interest to declare.

\section{Ana Maria Lopez Calvo de Feijoo}

PhD em Filosofia; Professora do Programa de Pós-Graduação em Psicologia Social da Universidade do Estado do Rio de Janeiro - UERJ (Rio de Janeiro, RJ, Br).

Rua Barão de Piracinunga, 62 - Tijuca

20520-170 Rio de Janeiro, RJ, Br

e-mail: ana.maria.feijoo@gmail.com

\section{Cristine Monteiro Mattar}

Doutora em Psicologia Social; Professora Adjunta II da Universidade Federal Fluminense

- UFF (Rio de Janeiro, RJ,.Br)

Rua Mariz e Barros, 128/404 B - Icaraí

24220-121 Niterói, RJ, Br

e-mail: cristinemattar.cm@gmail.com

\section{(cc) BY-NC}

This is an open-access article, which permits unrestricted use, distribution, and reproduction in any medium for non-commercial purposes provided the original authors and sources are credited. 